\title{
Identification and treatment of risk factors for coronary heart disease in general practice: a possible screening model
}

\author{
ALAN JONES, D H DAVIES, J R DOVE, M A COLLINSON, PAMELA M R BROWN
}

\begin{abstract}
A screening programme for the identification of risk factors for coronary heart disease in all patients aged $25-55$ years in a general practice population was studied.

The identification of risk factors included measurement of obesity, blood pressure, hypercholesterolaemia, and urinalysis, together with questions about family history, cigarette smoking, alcohol intake, and lifestyle. The patients with identified risk factors were invited to attend a lifestyle intervention clinic organised by the practice nurses and run by the health visitors, with the help of the local authority dietitian. Of $2646(62 \%)$ patients who attended for screening, $78(64 \%)$ of the 121 shown to have a high cholesterol concentration experienced a drop in cholesterol concentration. The mean fall in cholesterol concentration in the $\mathbf{7 8}$ patients who showed a positive response to intervention was $1.1 \mathrm{mmol} / \mathrm{l}$.

The study was intended as a possible flexible model for screening for coronary heart disease in general practice that could be complemented rather than replaced by opportunistic screening. The issues of organisation, cost, manpower, nonattendance, and effectiveness in a busy general practice environment are discussed.
\end{abstract}

\section{Introduction}

Though deaths from coronary heart disease in America, Japan, Australia, Belgium, and Holland have declined in recent years, no such decline has occurred in England and Wales. ${ }^{\prime}$ In a recent study ${ }^{2}$ in 24 British towns over a quarter of all the men studied showed evidence of coronary heart disease. ${ }^{2}$

Health Centre, Gorseinon, Swansea SA4 2US

ALAN JONES, MRCGP, general practitioner

D H DAVIES, $\mathrm{MB}, \mathrm{CHB}$, general practitioner

J R DOVE, $M B, B C H$, general practitioner

$M$ A COLLINSON, MB, BS, general practitioner

$M$ R BROWN, MB, CHB, general practitioner

Correspondence to: Dr Jones.
The relation of coronary heart disease to social class ${ }^{3}$ and the still widening differences in social inequalities, together with the unique role of the consultation with a general practitioner in primary care makes screening for cardiovascular disease in general practice eminently feasible. ${ }^{45}$

The most common factors contributing to coronary heart disease are smoking, raised total cholesterol concentrations, and hypertension; and family history, lack of exercise, obesity, alcohol intake, stress, and diabetes all contribute. Opportunistic screening is a way of screening a population but at present it is still only likely to be highly effective among the enthusiastic minority.

Patients at high risk of acute myocardial infarction are likely to be identified by opportunistic screening, especially if they are already known to have hypertension, ischaemic heart disease, diabetes, or angina or are smokers or have a family history of myocardial infarction. ${ }^{6}$ The screening of patients at very high risk, however, is likely to identify fairly few patients, but mass screening of patients with only moderate risk factors, such as moderate hypertension or hyperlipidaemia, is likely to show far more patients at risk. ${ }^{7}$ Multifactorial intervention trials have so far not fulfilled expectations, ${ }^{8}$ but for those who support mass screening of the population for moderate to high risk factors for coronary heart disease the question of how to screen the population simply, cheaply, effectively, and without causing anxiety must be tackled. ${ }^{9}$

The fact that nurses are now performing some of the simple procedures that experts have made so complicated ${ }^{10}$ and the introduction of desktop autoanalysers (Reflotron, Boehringer Mannheim) for use in general practice means that mass screening of the adult population for coronary heart disease is an imminent practicality rather than idealistic rhetoric. Measuring concentrations of fibrinogen or low density lipoproteins may well identify other important risk factors, ${ }^{112}$ but screening the population without performing venepuncture or obtaining fasting samples may well increase patient compliance. The whole screening procedure also remains quick and fairly inexpensive.

\section{Patients and methods}

The aim was to design a screening programme to identify risk factors for coronary heart disease in general practice over a short period that could be complemented rather than replaced by opportunistic screening. ${ }^{13}$ This was 
intended as a flexible model for screening for coronary heart disease in primary health care. We also intended to test the feasibility of such a screening programme in terms of time, manpower, patient compliance, and expense in a busy general practice and to assess the effectiveness of a programme of intervention in diet and lifestyle organised with the resources of the primary health care team.

Our practice of five partners with two trainees serves 10000 patients. There are two attached district nurses and two health visitors with 12 ancillary staff. A screening programme for male and female patients aged 25-55 was organised, the patients being identified from the computer age/sex register and being invited to attend by letter.

A questionnaire suitable for computer analysis was designed to encompass the known risk factors for coronary heart disease together with other information that we thought might be useful in later research. The questionnaire covered the following known risk factors: age, sex, social class, unemployment, previously documented ischaemic heart disease, hypertension, diabetes, and a family history of coronary heart disease risk factors in addition to details of physical activity and exercise, stress, cigarette smoking, alcohol intake, and oral contraceptive history among the women. Social class was determined by the Office of Population, Censuses and abnormalities were referred for full investigation and treatment. A flow diagram (fig 2) was constructed to enable the study nurses to follow the screening procedure clearly and easily. The clinics were held in the daytime or evenings to accommodate patients who worked, and the patients were further randomly divided into two groups to be seen either by the local authority dietitian or by the practice health visitor. Both gave similar advice on diets, supported by leaflets obtained from the Health Education Council, the Flora Heart Project, and Heartbeat Wales, and a further study was organised to examine the relative effectiveness of the advice given by the dietitian and health visitor, respectively. Patients were seen monthly for three months, and cholesterol concentrations were reported during and after the study.

Advice on smoking was given with the aid of leaflets, video tapes, and a carbon monoxide monitor (Bedfont Technical Instruments Ltd); this showed a direct quantitative improvement in patients after they received antismoking advice.

Two senior practice nurses were employed during the screening programme, each with an additional two nurses (SRN grade) and a receptionist. Thus teams of one senior nurse, two additional nurses and one receptionist formed a shift system from 9 am to $3 \mathrm{pm}$ and $3 \mathrm{pm}$ to $9 \mathrm{pm}$, respectively.

TABLE I-Reference ranges for factors used to classify patients studied and recommended action

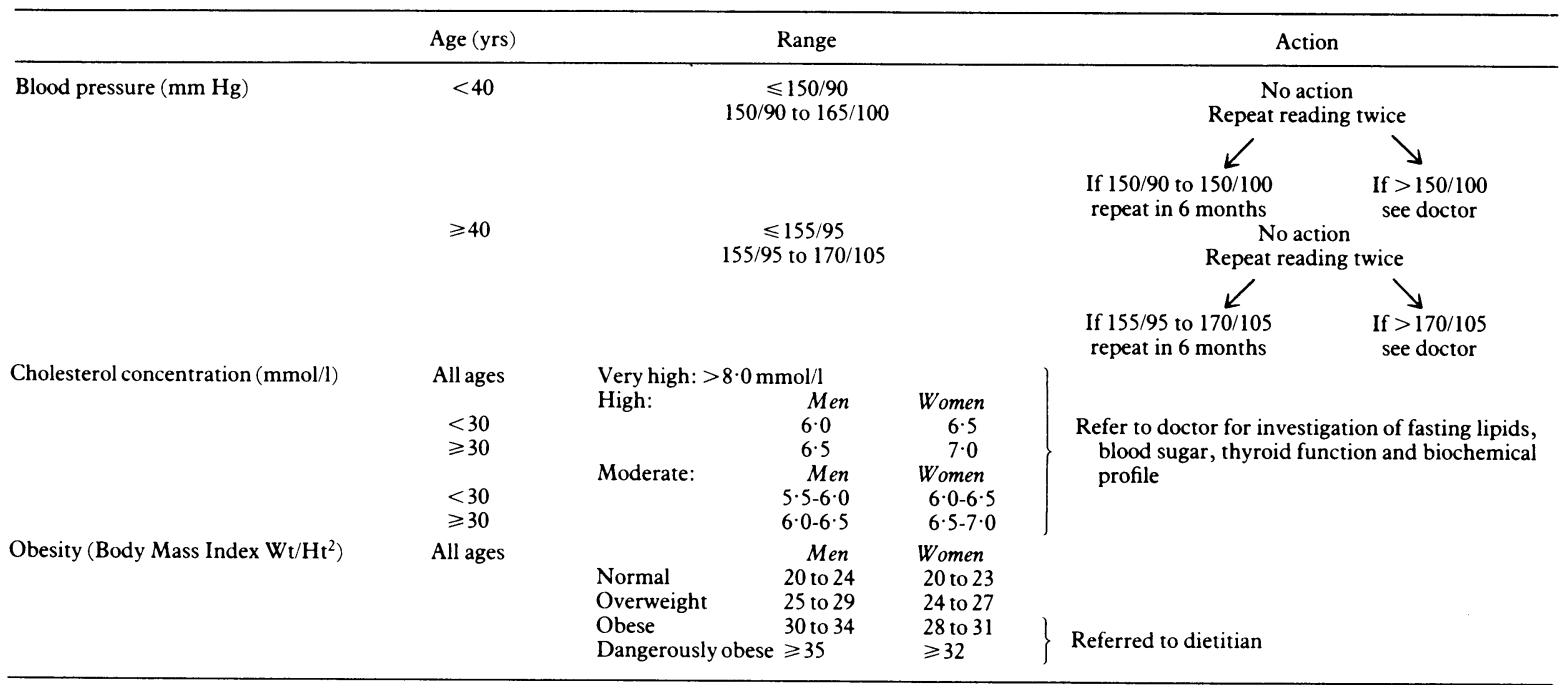

Survey's Classification of Occupations, 1980. The results obtained from the questionnaire were entered on a risk factor card, kept in our patients' notes (fig 1).

Physical examination included estimation of body mass index, measurement of blood pressure, urinalysis, and estimation of total plasma cholesterol concentration.

Body mass index was estimated as weight to the nearest $0.5 \mathrm{~kg}$ divided by the square of the height to the nearest $\mathrm{cm}$. Patients were weighed in light clothing and without shoes on standard Avery weighing scales, calibrated before the study. Height was measured with a calibrated metal measuring rule. Table I shows the classification for body mass index used.

Blood pressure was measured with a Hawksley mercury random zero sphygmomanometer, taking the mean of two readings taken on two occasions. The range of blood pressure used is shown in table I. Urinalysis was performed on fresh urine samples using BM-Test-3 (Boehringer Mannheim) for estimation of urinary sugar and protein concentrations.

Total plasma cholesterol concentration was estimated by the Reflotron system (Boehringer Mannheim) from fingerprick samples of whole blood. The nurses were trained in the use of the Reflotron, in particular to ensure that blood samples did not contain air bubbles that might give false low results. Quality control was carried out by measuring blind total plasma cholesterol concentration in numbered specimens sent to the biochemistry department, Singleton Hospital, Swansea, and the Heartbeat Wales laboratory at Cardiff. All patients with cholesterol concentrations $>8.0 \mathrm{mmol} / \mathrm{l}$ had fasting lipid estimations carried out as well as tests of blood sugar concentration, thyroid function (T4) and renal and liver functions.

All patients with raised cholesterol concentrations without secondary causes or familial hypercholesterolaemia were referred to our cholesterol clinic, held weekly at the health centre. Patients shown to have any of these

\begin{tabular}{|l|l|l|l|l|l|l|l|}
\hline Name: & & & & & & & \\
\hline Date & & & & & & & \\
\hline Smoking & & & & & & & \\
\hline Blood pressure (1) & & & & & & & \\
\hline Blood pressure (2) & & & & & & & \\
\hline Cholesterol & & & & & & & \\
\hline Body mass index & & & & & & & \\
\hline Urine & & & & & & & \\
\hline Exercise & & & & & & & \\
\hline Family history & & & & & & & \\
\hline Alcohol & & & & & & & \\
\hline Stress & & & & & & & \\
\hline Others & & & & & & & \\
\hline
\end{tabular}

FIG 1-Risk factor card used to record results obtained from questionnaire completed by patients. 


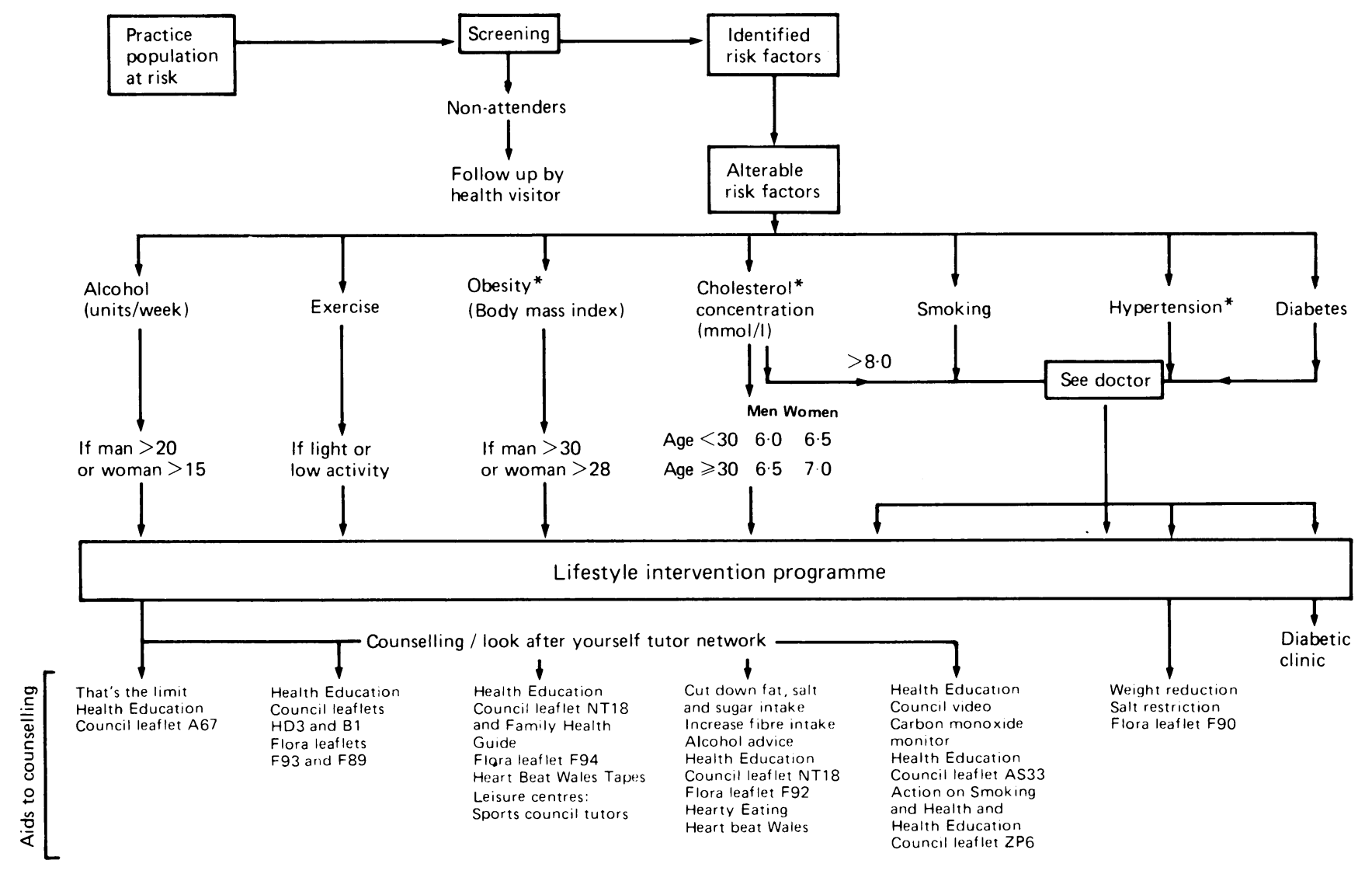

FIG 2-Flow diagram used by nurses in study to follow screening procedure.

The results were fed into the practice computer (Computer Analyst Programmers-General Practitioner System) from each shift worked. The estimated time needed to complete the study based on a $75 \%$ attendance was 10 weeks.

\section{Results}

Of the 3800 patients in the age range $25-55,2353(62 \%)$ attended for screening. The social class, sex, and age of the attenders were recorded. The distribution of patients who smoked (table II), had hypertension (table III), and had raised cholesterol concentrations (table IV) is shown in relation to both sex and social class (table II).

We identified no patients with all three of the highest risk factorsnamely, a very high cholesterol concentration, a heavy smoking habit, and hypertension, but there were two patients with a high cholesterol concentration who were smokers and had hypertension. Forty eight patients were found to have glycosuria and 51 patients proteinuria. The prevalence of smokers (table III) rose in the lower social classes, with more men smoking than women in all classes except social class 4 , where there were conversely almost twice as many women smokers as men. The prevalence of hypertension (table IV) also rose with social class for classes 3 to 5 , being greater in men than women. Social class 2 showed an even distribution for the sexes, and no patients with hypertension were found in social class 1 .

There were 221 patients with raised cholesterol concentrations, 171 (103 men and 68 women) in the high group and 50 ( 35 men and 15 women) in the very high $(>8 \mathrm{mmol} / \mathrm{l})$ group. All patients were invited to attend the lifestyle

TABLE II-Number (percentage) of smokers in relation to social class

\begin{tabular}{lcccccc}
\hline & \multicolumn{6}{c}{ Social class } \\
\cline { 2 - 7 } & 1 & 2 & 3 & 3 Manual & 4 & 5 \\
\hline Men & $20(11)$ & $65(12)$ & $53(13)$ & $124(18)$ & $49(18)$ & $53(21)$ \\
Women & $12(7)$ & $55(10)$ & $59(14)$ & $95(14)$ & $64(24)$ & $54(22)$ \\
\hline
\end{tabular}

TABLE III-Number (percentage) of patients with raised blood pressure in relation to social class

\begin{tabular}{lcccccc}
\hline & \multicolumn{8}{c}{ Social class } \\
\cline { 2 - 6 } & 1 & 2 & 3 & 3 Manual & 4 & 5 \\
\hline Men & 0 & $3(0 \cdot 5)$ & $10(2)$ & $17(2 \cdot 5)$ & $8(3)$ & $7(2 \cdot 8)$ \\
Women & 0 & $4(0 \cdot 7)$ & $5(1)$ & $11(1 \cdot 6)$ & $5(1 \cdot 8)$ & $7(2 \cdot 8)$ \\
\hline
\end{tabular}

TABLE IV-Number (percentage) of patients with high cholesterol concentrations in relation to social class

\begin{tabular}{lcccccc}
\hline \multicolumn{7}{c}{ Social class } \\
\cline { 2 - 7 } & 1 & 2 & 3 & 3 Manual & 4 & 5 \\
\hline Men & $2(1)$ & $9(1 \cdot 6)$ & $5(1 \cdot 2)$ & $10(1 \cdot 5)$ & $5(1 \cdot 8)$ & $2(0 \cdot 8)$ \\
Women & $2(1)$ & $3(0 \cdot 5)$ & $4(1 \cdot 0)$ & $3(0 \cdot 4)$ & $3(1 \cdot 1)$ & $2(0 \cdot 8)$ \\
\hline
\end{tabular}

intervention clinic. Of the 221,181 attended, of whom 121 returned for the final cholesterol check at three months. Of these $121,78(64 \%)$ showed a drop in cholesterol concentration and $43(36 \%)$ did not. The overall mean (SD) fall in cholesterol concentration in the 121 patients who completed the study was $0.74 \mathrm{mmol} / \mathrm{l}(0 \cdot 18)(95 \%$ confidence interval), while the mean difference for the 78 patients who showed a drop in cholesterol concentration was $1.1 \mathrm{mmol} / \mathrm{l}(0 \cdot 17)(95 \%$ confidence interval.) Imprecision was calculated from 18 replicate analyses, over nine days, of a commercial quality assurance serum (Precipath, BCL). The coefficient variation was $7 \cdot 5 \%$ at a mean concentration of $6.1 \mathrm{mmol} / \mathrm{l}$. Inaccuracy was assessed by analysis of nine samples of whole blood anticoagulated with heparin. Plasma was separated from duplicate samples and its cholesterol concentration measured at the department of chemical pathology, Singleton Hospital, Swansea, by an enzymatic method (BCL). The mean of the Reflotron results was $108 \%$ of the mean of the laboratory results. 


\section{Cost of the study}

Each of the two "shifts" consisted of one senior nurse $(£ 5 / \mathrm{h})$, two junior nurses $(£ 4 / \mathrm{h})$, one receptionist $(£ 2.50 / \mathrm{h})$, and one secretary/computer processor $(£ 4 / \mathrm{h})$ for five hours a week). In addition, one nurse $(£ 4 / \mathrm{h})$ worked each Saturday morning for a further three hours. The total manpower cost of the study was thus $£ 10150,70 \%$ of which was reimbursed by the family practitioner committee. Such an increase in manpower, however, will certainly mean that the maximum of two ancillary staff per doctor in general practice will be exceeded. As this occurred only in the 10 week screening period our family practitioner committee kindly waived this figure to average over the whole year. The total postage cost of our study was $£ 520$, making the effective cost to the practice $£ 3564$. Offering tetanus vaccination affords reimbursement of $£ 2.50$ per vaccine, together with the dispensing fee claimed after purchasing the vaccine en bloc. We used the screening programme as an additional means of encouraging any women who had not had a recent cervical smear to attend for cytology. Further saving in postage was achieved while maintaining compliance by sending for husbands and wives simultaneously rather than working alphabetically and systematically through the age/sex register. Our study does not take into consideration the cost of the Reflotron or the strips, both of which were provided by Boehringer Mannheim Ltd. The overall net cost of the study to a 10000 patient practice was $£ 3500$, or for the average 2000 patients per doctor practice the net effective cost was $£ 700$ per partner.

\section{Discussion}

The aim of this paper is not to give a comprehensive analysis of the prevalence of risk factors found but to describe a possible model for screening whole practice populations that could be used in primary care. Regular practice meetings of all the partners and participating staff helped to engender enthusiasm and momentum in the study. Several results are, however, interesting. The distribution of smokers by sex and social class was generally similar to that in other studies ${ }^{14}$ except in social class 4 , where we found a reversal with almost twice as many women smoking as men. The distribution of patients with hypertension was similar to that shown by Shaper et $a l^{15}$ and Marmot $e t a l^{4}$ in that those in manual social classes had higher blood pressures than those in non-manual social classes. No patients with hypertension were identified in social class one and only $1 \%$ in social class 2 . This may have been because more patients attended who were known to be from these higher social classes as a result of the practice's participation in the Medical Research Council's mild to moderate hypertension study in 1980

The quality control of the Reflotron showed the mean result to be $108 \%$ of the mean of the laboratory results. As the cut off points in our study (table 1 ) were well above the recommended values ${ }^{17}$ and as all patients with high values were screened further at the laboratory the chances of missing patients with hypercholesterolaemia were very slight.

The distribution of patients with raised cholesterol concentrations was almost uniform for all social classes. This differs from the findings of the British Regional Heart Study, which showed higher cholesterol concentrations in the higher social classes. ${ }^{16}$ Our results support the findings of Heartbeat Wales Clinical Survey (Welsh Heart Programme clinical survey unpublished observations). Again, the cholesterol concentrations of the non-attenders, when they are identified, may alter the overall picture of the distribution of raised cholesterol concentrations in our population. Forty three patients $(36 \%)$ who completed and complied with the three month lifestyle intervention programme showed no change in their cholesterol concentrations and were offered drug treatment, and it was decided that identified risk factors such as hypertension, diabetes, or smoking would be given special attention.

The monetary and health implications of the study become clear when we consider that $10 \%$ of our population had high cholesterol concentrations, of whom $64 \%$ showed a positive response to the lifestyle intervention without drug treatment. We can therefore positively influence $6.4 \%$ of the population easily without drugs or even identifying the non-attenders. If a $1 \%$ fall in cholesterol concentration gives a $2 \%$ drop in risk of coronary heart disease this $6.4 \%$ of patients alone makes this type of programme worth while. The benefit of identifying and treating the patients with hyper- tension, smokers, diabetics, or the obese is of course substantial but more difficult to quantify.

The response rate $(62 \%)$ in our study may seem disappointing, but patients received only one reminder letter and we used no advertising or publicity. Other such studies, in particular the Welsh Heart Programme, have shown that advertising such a health promotion exercise unquestionably helps compliance.

The identification and treatment of the non-attenders is regarded as very important and is the subject of a further and more detailed study. Future work must also concentrate on the moderately raised concentrations of cholesterol, even if we do not aim at the optimum $5 \cdot 2 \mathrm{mmol} / \mathrm{l}$ recommended. ${ }^{17}$

An important part of any such screening programme is the people who provide the lifestyle intervention counselling. In our case our own health visitors plus the local authority dietitian and, to a lesser extent, the screening nurses were totally responsible. The training of health visitors as "look after yourself tutors" is invaluable and must be encouraged. We believe that this study shows the usefulness of a community based dietitian as her attendance in a practice can greatly influence such a screening programme. The developing role of the practice nurse and the primary health care facilitator can also enhance such a programme.

In our study much of the total cost was offset by payment for items of service provided, for example tetanus vaccines or cervical smears. If the suggestions made by a recent government white paper are implemented it is conceivable that doctors could be paid a fee to encourage the provision of a health check such as the identification and treatment of risk factors for coronary heart disease in general practice.

We thank the following members of the primary health care team at Gorseinon Health Centre for their invaluable effort in this study: Gwyneth Linnard and Margaret Lyall; Jean Hunt and J Patterson; Jayne Spratley; Sue Rees and Lynne Deans for computing; and all the ancillary nurses and reception staff. Our thanks to Bayer UK Cardiovascular for their support and to West Glamorgan Area Health Authority for its cooperation and to Dr W O Williams, Swansea Research Unit; Professor J Catford, Welsh Heart Programme; Professor Nigel Stott, department of general practice, University of Wales College of Medicine; and Dr Ian Hainsworth, Singleton Hospital, Swansea, for their helpful comments. Our thanks to Dr Alan Sykes, University College, Swansea, for statistical advice and to Anne Griffiths for typing the manuscript.

\section{References}

1 Pisa $\mathrm{Z}$, Uemura $\mathrm{K}$. Trends of mortality from ischaemic heart disease and other cardiovascular diseases in 27 countries 1968-1977. The World Health Statistics Quarterly 1982;35:11-6.

2 Shaper AG, Cook DG, Walker M, MacFarlane PW. Prevalence of ischaemic heart disease in middle aged British men. Br Heart $\mathcal{F}$ 1984;51:595-605.

3 Marmot MG, Adelstein AM, Robinson N, Rose GA. Changing social class distribution of hear disease. BrMed J 1978;ii: 1109-12.

4 Marmot MG, McDowall ME. Mortality decline and widening social inequalities. Lance 1986;ii:274-6.

5 Stott NCH, Davies RH. The exceptional potential in each primary care consultation. $f R$ Coll Gen Pract 1979;29:201-5.

6 Shaper AG, Pocock SJ, Phillips AN, Walker M. Identifying men at high risk of heart attacks: strategy for use in general practice. BrMed f 1986;293:474-9.

7 Kannel WB, Gordon T. Some characteristics related to the incidence of cardiovascular disease and death; Framingham Study, 16 year follow up. Section 26. Washington, DC: US Government Printing Office, 1970 .

8 British Cardiac Society Working Group on Coronary Disease Prevention. Report. London: British Cardiac Society, 1987

9 Oliver MF. Strategies for preventing and screening for coronary heart disease. Br Heart $\mathcal{J}$ $1985 ; 54: 1-5$

10 Hart JT. Coronary prevention in Britain: action at last? Br Med f 1987;294:725-6.

11 Stone MC, Phorp JM. Plasma fibrinogen-a major coronary risk factor. $\mathcal{f} R$ Coll Gen Pract 1985;35:565-9.

12 Meade TW, Mellows F, Brozovic M, et al. Haemostatic function and ischaemic heart disease: principal results of the Northwick Park Heart Study. Lancet 1986;ii:533-7.

13 Scientific and medical advisory committee of the Coronary Prevention Group. Risk assessment its role in the prevention of coronary heart disease: recommendations of the scientific and medical advisory committee of the Coronary Prevention Group. Br Med J 1987;295:1246.

4 Fowler G. Smoking. Br Med F 1982;284:1306-8.

15 Shaper AG, Pocock SJ W W alker M, eal. British regional heart study: cardiovascular risk factors in middle aged men in 24 towns. Br Med $f$ 1981;283:179-86.

16 Thelle DS, Shaper AG, Whitehead TP, et al. Blood lipids in middle aged British men. BrHeart f 1983;49:205-13.

17 Study Group of the Atherosclerosis Society. Strategies for the prevention of coronary heart disease: a policy statement of the European Atherosclerosis Society. Eur Heart $\mathcal{f}$ 1987;8:77-88.

(Accepted 4 March 1988) 